\title{
Teaching Caste \& Reservation in Classroom Setting: Effort towards Anti-oppressive Social Work Practice
}

\author{
Prof. Sanjoy Roy \\ Professor, Department of Social Work, University of Delhi, India, Delhi-110007. \\ Email: sanjoyroy30@gmail.com
}

\section{ABSTRACT}

On the whole and equal representation of the people serve a sense of identity for the nation building for any country in the world. A country of assimilating people across borders is one nation and reflects common sentiments. Therefore communities which are backward education- ally, economically, culturally and in other respects, should be given more priority for their overall development. In India there have been specified many backward class communities and their movements in terms of caste or reservation. Though, it is observed in the last two centuries that apart from the upward surge in population of India; there is still inequality and underrepresentation of the various communities especially SCs, STs or OBCs in all spheres. The present article has analysed the true sense of reservation and caste discrimination as a structural problem and how these particular groups lacks in many spheres of their lives using qualitative analysis of thirty respondents from Delhi. Questionnaire was used as a tool for the data collection. At the end, it will be substantial to say that teaching caste and reservation in classroom setting has a meaning of providing awareness, advocacy and understanding about the government programmes, policies,

KEYWORDS : Caste, Reservation, Affairmative Action, Political Representation, Justice

\section{Introduction}

Indian society is characterised by a high degree of structural inequalities, based on the institutions of caste and ethnicity. Although every caste (except those at the top of our caste hierarchy) suffers from the unequal and hierarchal assignment of rights, it is the 'untouchables 'castes referred to officially as the Sched-uled Castes (SCs) which have suffered most. Historically they were denied the right to property, business (except some occupa- tions considered as impure and polluting), education, and all civil, cultural and religious rights, except manual labour and service to castes above them.

Untouchables also suffer from residential segregation and social isolation (Thorat, 2005). Another source of exclusion is linked with ethnic identity, from which groups like the Adivasis (meaning indigenous) referred to officially as Scheduled Tribes (STs) suffer. This group has suffered from isolation, exclusion, neglect and underdevelopment due to their geographical and cultural isolation. In their case, exclusion can take several forms, including the denial of right to resources around which they live, and displacement induced by economic development. It is true that the period of restoring an independent India and holistic representation of the people served a sense of identity in nation building.

In their case, exclusion can take several forms, including the denial of right to resources around which they live, and displacement induced by economic development. It is true that the period of restoring an independent India and holistic representation of the people served a sense of identity in nation building. A country of assimilating people across borders is one nation and common sentiments.
B.K Roy Burman's Beyond Mangal and After: This Backward Class Movement from the 1920's-1930's onwards spread its ideology towards 1953's Backward Class Commission culminating in the pillars of affirmative actions. However, it is observed in the last two centuries that apart from the upward surge in population of India; there is still inequality and underrepresenta- tion of the various communities in all spheres. The smaller commu-nities identify itself with the larger communities for security. It is not all caste, sub castes, tribes that are truly represented.

\section{Demography}

Scheduled Castes (SCs) which were ex-untouchables are now popularly known as 'Dalits' along with Scheduled Tribes, are historically disadvantaged groups in India. SCs and STs average population is $18 \%$ \& $8 \%$ consequently. Other Backward Castes include mostly Hindu low castes and some non-Hindu communities are also included in OBCs. Some tribes which are not included in ST category are also put in OBCs category. OBCs constitute $43 \%$ of the rural and $39 \%$ of the urban population (National Sample Survey 2009-10). The number of Scheduled Castes (SCs) in India increased by 35 million during the decade ranging from 2001 to 2011 .

This means that there are now 201.4 million Hindu, Sikh and Buddhist Dalits in the country. The increase of 20.8 per cent is somewhat higher than the general population increase of 17.7 per cent. This means that the overall SC share of the population has grown from 16.2 to 16.6 per cent. India's demographic imbalance is reflected in the number of SCs of which there are 103.5 million males and 97.9 million females (Census, 2011). 
But the regret part of the fact is that more than three fourths of India's SCs are still living in rural areas, but since the 2001 census, there has been a 40 per cent increase in the number of SCs living in urban areas. This figure is now approaching 50 million, while more than 150 million still live in rural India. India's Scheduled Castes are distributed across 31 states and union territories. The states with the highest total numbers of SCs are Uttar Pradesh, with more than 40 million, and West Bengal with approximately 20 million. The less populous Punjab is the state with the highest proportion of SCs to its total population -31.9 per cent.

While the 200 million SC's constitute a significant proportion of India's population, the total, if unofficial, number of Dalits in the country is almost certainly considerably higher, as Christian and Muslim Dalits are not registered as 'Scheduled Castes'. Hence, they are not entitled to so-called 'reservations' in the education system and government jobs and other constitutional safeguards in the true sense.

On the other hand, the Scheduled Tribes population like Adivasis/ tribals, who constitute $8.6 \%$ of the country's total population, are concentrated unevenly indifferent regions of the country. A little over $80 \%$ of the tribal population lives in the contiguous regions of eastern, central and western India. Another nearly $12 \%$ inhabits the northeastern region, over $5 \%$ is in southern India, $2 \%$ in northern India and much less than $1 \%$ in the island region of India (Virginius Xaxa, (2018). At the all-India level, there are 635 tribal groups spread all over the country, of which 75 tribes have been identified as Particularly Vulnerable Tribal Groups (PVTGs) (Census, 2011). Major Problems of SCs \& STs who have been facing are social oppression and injustice, economic backwardness, low educational attainment, health issues, development-induced displacement, political marginalization. The culture of poor and marginalised group does not exist in vacuum. It is in constant and dynamic interaction with the matrix of political, economic and social factors in which it is embedded (Stein- berg, 1998:10)

\section{Post-Independence India, 1947: A New beginning!}

Our founding fathers of Indian Constitution were well aware of the entrenched and cumulative nature of group inequalities prevailing in the name of social evils of caste system. Therefore constitutional policies were designed to offset these entrenched discriminatory practices. Thus independent India came to embrace equality as a cardinal value against the background of elaborate, valued and clearly perceived inequalities. The result has been an array of programmes that are termed here as policy of Protective or Compensatory Discrimination.

In fact the measures for ensuring equal protection of laws involve the element of protection as well as that of compensation or repara- tion to offset the systematic and cumulative deprivations suffered by lower castes in the past. These protective discrimination policies are authorised by constitutional provisions that permit departures from norms of equality, such as merit, even handedness and indifference to inscriptive characteristics (Marc Gallanter, 1990). This array of protective discrimination programmes can roughly be divided into three broad categories. First are Reservations which allot or facilitate access to valued positions or resources; such as reservations in legislatures, including the reservations for Scheduled castes and scheduled tribes in Lok Sabha (House of the People; the lower house of Indian Parliament), reservations in govern-ment services and reservations in educational institutions. Second type of protective measures are employed though less frequently in land allotment, housing and other scarce resources like, scholarships, grants loans and health care etc. Third type of protective measures is specific kinds of action plans for removal of untouchability, prohibition of forced labour etc. Interestingly few in independent India, would voice the disagreement with the proposi-tion that the (Verinder Grover, 1998).

It may be noted that initially these reservations were provided for only 10 years from the commencement of the Constitution under article 334 of the Constitution. But this duration has been extended continuously since then by 10 years each time. Now the period of reservations in Lok Sabha and State legislative assemblies stands for 70 years from the commencement of the constitution. It is felt that the handicaps and disabilities under which these people live have not yet been removed and that they need this reservation for some time more so that their condition may be ameliorated and they may catch up with the rest of the nation. The number of Lok Sabha seats reserved in a state of Union territory for such castes and tribes is to bear as nearly as possible the same proportion to the total number of seats allotted to that state or Union Territory in the Lok Sabha as the population of the scheduled castes and scheduled tribes in the concerned state or Union Territory bears to the total population of the state or the union territory.

The fact that reservation of seats for scheduled castes and scheduled tribes in the legislatures is not on a permanent basis, but is at present provided for 10 years period at a time, shows that it is envisaged that the scheduled castes and scheduled tribes would ultimately assimilate themselves fully in the political and national life of the country so much so that there would be no need for any special safeguards for them and there would be no need to draw a distinction between one citizen and another. Their condition would improve so much that they would feel their interests secure without any kind of reservations.(V.V.Giri v. D. Suri Dora, AIR 1959 SC 1318 in M.P.Jain, Indian Constitutional law, Wadhwa and Company Pub, Nagpur, 1997).

This has a long history, Mahatma Gandhi has undergone a long fast to protest against the Ramsay Mc Donald award, for separate electorate in 1932 resulting into Poona Pact, under which it was agreed to have joint electorate but reservations in legislative bodies. This particular provision was given concrete shape in the Government of India Act of 1935 (Bipan Chandra, 1990). In India, the living standard of Scheduled Tribe, Scheduled Caste, Other Backward Classes are much more vulnerable than other mainstream population. The state is the most important element for defining the various social categories for material rewards mostly on job and education. 
The affirmative action policies give an access to education and employment guaranteed by Article 46 that states that State shall promote with special care the educational and economic interests of the weaker sections of the people, and, in particular, of the Scheduled Castes and the Scheduled Tribes, and shall protect them from social injustice and all forms of exploitations.

Similarly, the Indian Constitution in Article 341 specify the castes, races or tribes or parts of or groups within castes, races or tribes that shall be Scheduled Castes in relation to that State or Union territory which parliament by law may include in or exclude from the list of Scheduled Castes and Article 342 specify the tribes or tribal communities or parts of or groups within tribes or tribal communities which shall for the purposes of this Constitution be deemed to be Scheduled Tribes and Parliament may by law include in or exclude from the list of Scheduled Tribes of the Indian Constitution.

The Government decision to grant $10 \%$ reservation (One Hundred and Third Amendment), 2019 to economically weaker sections (EWS) of the General category was a welcome move in the beginning of 2019. The criteria are: the total income should not be more than eight lakhs in Indian Rupees (INR) and should not possess the following conditions-landholding above five acres / residential flat of 1000 square feet/residential plot of 100 square yard in notified municipality/ residential plot of 200 square yard and above in areas other than the notified municipality. However in education sector both in public and private institutions; the EWS category exceeds $10 \%$. This quota system will make a total of more than $50 \%$ ( $7 \%$ for scheduled caste, $15 \%$ for scheduled tribes, $27 \%$ for $\mathrm{OBC}$ and $10 \%$ for General category) (Padmanabhan, 2019) (Tripathi, 2019). This Amendment for the first time recognises $10 \%$ for the General category population.

However, implementing the certification and documentation process for land holding will be cumbersome as majority of the population are not acquainted with the bureaucratic process in the government offices. Efforts of digitization of documents related to land and revenue is still not streamlined leaving the metropolitan areas. Internet connectivity and accessibility is also not easily reached uniformly in various parts of India.

So, there is sufficient evidence that amply demonstrates the various aspects of stigmatization, exclusion and rejection that Dalits continue to face in contemporary India. In rural India, despite the breakdown of the traditional subsistence economy, caste continues to exert its strong presence in many different dimensions. (Human Rights Watch (1999, Shah et al. (2006).
From 2014 onwards, the Planning Commission is replaced by NITI (National Institute of Transforming India) AYOG, an advisory body based on cooperative federalism for a period of three years. Studies (Zwart, 2000) have revealed that the economic and socially backward classes of India look for affirmative action as a remedy. Thereby, affirmative action is must for these disadvantaged groups like SCs, STs and Other Backward Groups who have been compromised historically, in terms of redistributes economic means, educational benefits and offices ensuring government power to make collective action.

Affirmative action programme are the tools to remove the present and continuing effects of past discrimination, to lift the limitations in access to equal opportunities which has been impeding the access of the classes of people to public offices and administration. Such measures as protective discrimination or reservations are adopted to remedy the continuing ill effects of prior inequalities stemming from discriminatory practices against various classes of people which have resulted in their social, educational and economic backwardness. It also addresses the infirmities caused due to purposeful societal discrimination and attacks the perpetuation of such injustices. (Justice P.B.Sawant, in Indira Sawhney v. Union of India, AIR 1993, SC 477, Para 23.).

\section{Reservation and Affirmative Action by the Government}

\section{Government Services}

The most important aspect of the reservation policy is that relating to government services. Article 16 (4) of the Constitution of India empowers the State to make "any provision for the reservation in appointments, or posts in favour of any backward class of citizens", and "provision for reservation in matters of promotion to any class or classes of posts, in the services under the State in favour of the SCs and STs."

In pursuing this provision, the Government made reservation for SCs and STs in proportion to their share of population. There are also reservations in the promotion of employed persons. The government services included are the Government civil service, public sector undertakings, statutory and semi-Government bodies, and voluntary agencies which are under the control of the government or receiving grant-in-aid. At the central level, some services are however excluded from the reservation policy; these include, most prominently, defense and the judiciary.

Reservation is accompanied by other provisions designed to increase the ability of SCs and STs to compete for government jobs. These include the relaxation of minimum age for entry into the service, relaxation in the minimum standard of suitability (subject to a required minimum qualification), the provision of pre-examination training, separate interviews for SCs and STs, and representation of people with $\mathrm{SC}$ or ST backgrounds on selection committees. 


\section{Education \& Educational Institutions}

The second most important aspect of reservation policy relates to education. Article 15 (4) of the constitution empowers the State to make special provision for the educational advancement of SCs and STs. In pursuing this provision, the State reserves places for SC and ST students in educational institutions, including all colleges run by the Central or State governments and all government-aided educational institutions. This is supported by a number of financial schemes, including scholarships, special hostels for SC and ST students, fee concessions, grants for books, and additional coaching.

On the other hand, the two most contentious issues about providing reservations in educational institutions for scheduled castes and scheduled tribes are (1) Determination of backward class status and (2) extent or quantum of reservations. Determination of socially and educationally backward class status is not a simple matter as sociological and economic considerations come into play in evolving proper criteria for its determination. Article 340 contemplates appointment of a commission to investigate the conditions of socially and educationally backward classes and such other matters as are referred to the commission. Article 341 provides that the President of India may by notification in a particular state; after due consultations with governor in a particular state specify the castes, races or tribes which shall for the purpose of this constitution be deemed to be scheduled castes in relation to that state. The second clause of this article provides the list of scheduled castes specified in the notification issued under scheduled tribes. However, it may be noted that the courts are not precluded from going into the questions whether the criteria used by the state for the purpose are relevant or not (M.P. Jain, Indian Constitutional Law, Wadhwa and Company, Nagpur, 1997. 159 Moosa v. Kerala, AIR 1960, Ker 355.).

\section{Political representation and Reservation in Legislative Bodies}

The third most important sphere of the reservation policy relates to representation in Central and State legislatures. Under Articles 330, 332 and 334 of the Constitution, seats are reserved for SCs and STs in the Central legislature and State legislatures. Similar reservations are provided in local level bodies at district, Taluka and village level. The reservation of seats is complemented by statutory provisions to enhance political participation by SCs and STs.

The constitution of India treats the scheduled castes and scheduled tribes in India with special favour and affords them with some valuable safeguards. The scheduled castes are depressed sections of the Hindus who have suffered for long under social handicaps and thus need special protection and help for the amelioration of their social economic and political conditions.
Scheduled tribes also known as ab-origines, are those backward sections of Indian population who still observe their tribal ways, their own peculiar customs and cultural norms. The tribal people have remained backward because of the fact that they live in inaccessible forests and hilly regions and have thus been cut off from the main currents of national life (M.P.Jain, 1997). These scheduled tribes people too need special provisions for safeguarding their interests.

The main problem concerning these people is that their socio-economic conditions be improved at such a pace and in such a way as not to disturbed suddenly their social organisation and way of living. The need is to evolve ways and means to gradually adjust the tribal population to changed conditions and integrate them slowly in general life of the country without undue and hasty disruption of their way of living. For the purpose of providing protection in terms of political representation, article 330 of Indian Constitution provides that seats in proportions to the population of scheduled castes and scheduled tribes in particular states are reserved in the Lok Sabha.

The states which are predominantly tribal are excluded from the operation of article 330. Earlier section 2 of 23rd amendment of the constitution 1969, excluded the operation of article 330 to the tribal areas of Nagaland, but the exclusion has now been extended in respect of the state of Meghalaya, Mizoram and Arunachal Pradesh by 31 rst amendment Act as these states are predominantly tribal in nature. Similarly under article 332, seats are reserved in the legislative assemblies of the states in favour of scheduled castes and scheduled tribes in proportion of their population in that particular state.

Once again the state of Meghalaya, Nagaland, Mizoram and Arunachal Pradesh are excluded from the operation of article 332, simply because of the predominant tribal population in those states. Article 331 and 333 does the same in favour of members of Anglo-Indian Community. It is obvious that reservations of seats in Lok Sabha and legislative assemblies of the States in favour of scheduled castes and scheduled tribes is for the purpose of ensuring presence of minimum number of representatives of scheduled castes and scheduled tribes (V.N.Shukla, 1990).

Another issue relates to the quality of representation afforded by the SC and ST is in the legislature. Studies have indicated that they experience lower participation, less articulation, less assertion, and less independence than representatives from high castes. It has been argued that SC and ST from reserved constituencies are limited in their ability to represent their group interests, because the constituencies are still made up overwhelmingly of non-members of their groups. 
Because of this limitation, Dr. Babasaheb Ambedkar had originally suggested (in 1945) an alternative arrangement, known as the 'Separate Electorate', to ensure a more independent representation of SCs and STs in the legislature.

\section{Access to justice}

Another issue relates to the access of SCs and STs to the institutions of justice in seeking protection against discrimination. Studies indicate that SCs and STs are generally faced with insurmountable obstacles in their efforts to seek justice in the event of discrimination. The official statistics and primary survey data bring out this character of justice institutions. The data on Civil Rights cases, for example, shows that only $1.6 \%$ of the total cases registered in 1991 were convicted, and that this had fallen to 0.9\% in 2000. A study in Andhra Pradesh of the reasons for low conviction observed negligence and collusion at the stage of registration, charge sheeting and investigation, in seeking justice before the law in the court, and also in giving compensation (Agrwal and Gonsalves, 2005).

\section{Methodology}

The research is carried out to study the subjective understanding of caste and reservation as a structural problem in India especially in Delhi as many students come to study and job purposes. It is based on a qualitative analysis of thirty respondents (10 each from 3 categories) in the age group of 21-30 \& 30-50 years who are students of University Delhi (Capital of India), research scholars and educators (SC \& ST). Those respondents who were interested were instructed on the objective of the study. Questionnaire was used as a tool for the respondents to answer the subject. They also represented their Caste (General, Other Backward Class \& Other Backward Class) and Gender (Male/ Female and Others) in the study to show the type of response that is gathered in macro social conditions. An Inter-sectionalist understanding is kept into consideration.

No scholar can avoid cultural ideas and his or her placement in the intersecting oppressions of race, gender, class, sexuality and nation" (Collins, 2000). Since India is mostly a part of caste identity rather than race, caste is taken as a thematised area for consideration. This helps in understanding caste and reservation by creating meanings in everyday practice in our society especially in colleges, universities or offices. There are few themes which have emerged out of the study, and it is reflected through an inter-sectionalist approach of how it is identifying the form of discrimination and less privilege positions.
The study has aimed to show an anti-oppressive measure of dialogue and practice. The names of the respondents are not mentioned in the study maintaining confidentiality. The questions that were asked on the concept of caste and reservation, $10 \%$ reservation for generally economically disadvantaged population, affiliation to reserved categories, structural inequalities of caste, class, race, gender and the subjective experiences and lastly how much affirmative actions of the government changes the status of SCs \& STs till now.

\section{Findings \& Discussions}

This helps in understanding caste and reservation by creating meanings in everyday practice in our society especially in colleges, universities or offices. There are few themes which have emerged out of the study, and it is reflected through an inter-sectionalist approach of how it is identifying the form of discrimination and less privilege positions. The study has aimed to show an anti-oppressive measure of dialogue and practice. The names of the respondents are not mentioned in the study maintaining confidentiality. The questions that were asked on the concept of caste and reservation, 10\% reservation for generally economically disadvantaged population, affiliation to reserved categories, structural inequalities of caste, class, race, gender and the subjective experiences and lastly how much affirmative actions of the government changes the status of SCs \& STs till now.

It is observed mostly among the student communities that are being identified and labelled with grossly over generalized, deficit-laden characteristics that put them at risk of being viewed as less capable, less cultured, and less worthy as learners. While we do not want to underplay the stresses on some students/scholars/educators who live in discriminatory \& experiences, we do want to advocate for a perspective that sees these students/scholars/educators and their families as histories and cultural beings. Each of them has their own individuality in terms of individuality and that background needs to be respected and "Students from different backgrounds interpret information differently. It will be important to incorporate cultural lessons that have students take on different perspectives of other culture (Sato and Lensmire, 2009).

Inclusion of students in all realms of class room setting can help in achievement and performance of the students. Research suggests that inexperienced teachers and racial isolation are important factors to explain the achievement gap (Hanushek \& Rivkin, 2006). 
Student's knowledge can facilitate learning as they come from various backgrounds. Various method and tools like surveys, classroom observations, and follow-up conversations with participant are proposed by Ladson-Billings and Darling-Hammond to facilitate learning (2000). Another factors like on relationships and shared authority, linking classroom content with student experience, incorporation of familiar and culturally compatible communication patterns, and development of counter narratives that challenge typical conceptions of at-risk students and families can help in building coherence.

Similarly, urban teachers who put high priority in the educational success of children in poverty are typically involved in the development of counter narratives that challenge stereotypical ideas about the so-called at risk students, whether the students live in poverty and/or come from culturally and linguistically diverse backgrounds (Abbate-Vaughn, Frechon and Wright, 2000)

Every individual can experience a situation in question in very different ways. Nor does it reify the structural aspects that shape such situations, assisting in holding individuals responsible for their actions in a situation (Hancock, 2016). Haberman (2005) noted that educators engage in the production of counter narratives: responses that seem to go ever so-slightly or sometimes markedly, against the grain of stereotypical notions about low-income students of color thought of at-risk.

This study also has produced counter narratives from the perspective of living in a urban culture, exercising their rights and affirmative actions. Some of the complex and often unmentionable aspects of teaching in Delhi is the notion of colour, creed, religion, caste, inequality, discrimination etc. More positive and negative analysis has come out from the discussion. Many more perspectives of reservation and affirmative actions of the government brought to picture by the respondents like action of protective discrimination, reservation in practice and other programmes \& schemes and its positivity against anti-oppressive discrimination of SCs, STs \& OBCs in the society today.

\section{Action on Protective Discrimination}

According to Article 15 of the Indian Constitution, the State shall not discriminate against any citizen on grounds only of religion, race, caste, sex, place of birth or any of them be subject to any disability, liability, restriction or condition. Article 16 states making provision for the reservation of appointments or posts in favour of backward class citizens who are not adequately represented in the services under the State, provision for reservation in favour of the Scheduled Castes and the Scheduled Tribes who are not adequately represented in the services under the unfulfilled vacancies. These anti-discriminatory practices and equal opportunities for all provide a common platform for active participatory efforts.

\section{Reservations in Practice: The Reality}

In India today, admissions to government universities and hiring to government jobs or jobs in state-owned corporations are subject to hiring quotas. Reservations in private sector hiring and public sector promotion have been proposed but not widely implemented. However, the areas where reservation used are significant: public universities make up the majority of university seats and are considered the most prestigious, and public sector employment is considered both more secure and desirable than comparable private employment. Both university admissions and government recruitment in India are determined based on competitive written exams.

The highest scoring individuals are admitted or hired as the "general" quota. Then continue down the list, admitting the highest scoring SCs, STs and OBCs until the quotas for these groups are filled or until there are no applicants who meet a minimal quality threshold. Note that the percentage of members of underprivileged groups among the beneficiaries can be above $50 \%$ (if many applicants from these groups score above the general cutoff) or less than $50 \%$ (if most applicants from these groups score below the qualification cutoff). Sensitive to the criticism that this system provides an advantage to wealthier $\mathrm{OBC}$ jatis, some states (mostly in the south) have subdivided the OBC category into various subcategories, each with their own list and quota.

But, over time there has been a considerable increase in the share of SCs and STs in government employment and educational institutions. Reservations in the legislature have also provided a space for SCs and STs in the executive and in the decision-making process. The formal reservation policy in the government sector, and the general developmental and empowerment measures in the private sector, has also contributed to an improvement in the human development of SCs and STs. However, during the course of the implementation of India's reservation policy some problems have become apparent. First, the success of the policy has been uneven across sectors and departments. Second, the policy is limited to the government sector, while more than 90 percent of SC and ST workers are employed in the private sector. Finally, despite the improvement in human development among SCs and STs, disparities in attainment with non-SCs and non-STs persist even today. This indicates that addressing social exclusion is often a far more difficult challenge than anti-poverty policy.

Since 1990, after implementation of Mandal Commission Report $27 \%$ quotas for $\mathrm{OBCs}$ in jobs which extended to educational institutions via 93rd Constitution Amendment in 2006.Supreme Court put cap on reservation at $50 \%$ of the total jobs \& seats. $10 \%$ government jobs \& seats in educational institutions reserved in 2019 for economically backward upper castes citizens, who earn less than 8 lakhs rupees annually. 
The provisions of the Panchayats (Extension to Scheduled Areas) Act 1996/PESA law was enacted by Government of India and provided self governance through traditional Gram Sabhas for people living in Scheduled Areas. Scheduled Areas are identified by the Fifth Schedule. Scheduled Areas was not covered by $73 \mathrm{rd}$ Panchayati Raj Act. Therefore, PESA was enacted on 24th December 1996. Government has recognized the forest rights and occupation in forest land in forest dwelling Scheduled Tribes and other traditional forest dwellers who have been residing in forests for generations. The Act has provisions to provide fair compensation to those whose land is taken away and $70 \%$ consent of landowners is necessary for public private partnership (PPP) projects.

\section{The Right to Fair Compensation and Transparency in} Land Acquisition, Rehabilitation and Resettlement Act 2013 (Land Acquisition Act 2013) which ensure, in consultation with institutions of local self-government and Gram Sabhas established under the Constitution, a humane, participative, informed and transparent process for land acquisition for industrialisation, development of essential infrastructural facilities and urbanisation with the least .

Scheduled Caste Sub-Plan (SCSP) which provides resources to family oriented schemes of economic development of SCs below poverty line. 100\% grant is given by centre under Central Assistance (SCA) to scheduled castes sub plan. 27 States/ UTs who have having sizeable SC population are implementing schedules Caste Sub Plan.

The Tribal Sub Plan which is similar to SCSP, the Tribal Sub Plan (TSP) is also Government of India programme to channelize funds from the Planning Commission for the development of SCs and STs. TSP is a strategy for the rapid socio-economic development of tribal people. Funds should be in proportion to the ST population of the state/ UTs. The scheme is applicable in 22 States \& 2 UTs, Bihar is one of them. Thus, TSP aims at increasing family based income activities, employment generation, infrastructure development and empowerment of Tribals.

Some other Prominent SC/ST Welfare Programmes which need to be strongly implemented.

1. Dr. Ambedkar Chikitsa Yojna

2. Dr. Ambedkar Samajik Swasta Kendra Yojna

3. One time National Scholarship Scheme for SC/ST, Minorities student of 26 education board of the country.

4. Post-Metric Scholarship Scheme

5. Pre-Metric Scholarship Scheme

6. Establishment of Ambedkar Peeth

7. Centrally sponsored scheme of Hostels for SC \& ST boys and girls

8. Scheduled Castes and Schedules Tribes Act 1989.
In considering these findings and conclusions, it should be noted that the majority of respondents fell into the age range of college students, so these preferences and effects mostly summarize the belief systems, behaviors, and perceptions of college students and/or young adults. While some respondents at least 30 years old participated, further research could systematically explore the effects of Christian faith sharing through social media among different age groups. Furthermore, this study has the weakness of collecting data at a Christian college, probably resulting in a sample that contained a higher concentration of participants who would readily receive Christian faith sharing through social media. While many of the students do not actively practice the Christian faith, they have at least become accustomed to hearing the Christian message through this institution. Therefore, an option for future research would involve exploring these research questions using more diverse populations or focusing on non-Christians specifically in that research. Finally, the quantitative nature of this research did not allow for subjects to provide answers beyond the options provided, so further research should also take place in the subject area using qualitative measures as noted by Previte (2017). From this research and these other future recommendations, the common practice of Christian faith sharing may have a greater impact and less offensiveness for those who encounter their message.

\section{Summary and Conclusion}

Affirmative action policies aim at justice for the Dalits and other marginalised sections in the society. The extreme manifestation of such inequalities in India led to a growing awareness of the need for reform Affirmative Action policies are tools targeted to uplift the disadvantaged groups and elimination of caste system. Global events and immigration patterns have dramatically changed the cultural and political landscape of classroom in developed countries like India. It is important to understand and challenge the larger education system in order to help sustain a habitable and supportive ecosystem for diverse students. Critical thinking in education can help overcome structural problem (Gallagher, 2016).

The students coming from various backgrounds develop and utilize spaces of marginality within educational institutions and produce their rich experience to conscientize on the issue of caste and reservation. If the teachers are not empathetic to the situation or background of the students; then it will be a biased outlook for the teachers as they come with their own socio-cultural baggage and background. 
Practice of Group discussion, case work on the intersectional elements can remove the narrow- mindedness in the classroom. The Social Work Educators need to imagine and examine as educators and citizens; as complex, cultural, and historical beings; as human actors born into a web of meanings and values creating values (Sato \& Lensmire, 2009).

The students and practitioners need to learn how to respond in circumstances outside the classroom setting by developing awareness to observe socioeconomic \& cultural differences among the students; developing empathetic rapport and sensitive attitudes and commitment to culturally responsive teachings (multi-cultural) in our country. Developing a psycho-social consciousness and life experiences teaching of subjective account can help in the classroom setting which could be the practice area for social worker and also for the educators.

To construct anti-oppressive practice more entrenched in the class-room setting, social work educators should believe in writing texts, case study or notes on anti-oppressive incidents and discourse to make it simpler because students may struggle to understand or relate with the reality. Such texts or case study should be exact, accurate and concise and should emphasize with practical examples from the field, salient issues about oppressive practice in our country or even other countries and anti-oppressive strategies so that students would be well prepared, not only the knowledge ground but also the skills \& techniques necessary for challenging oppressive acts happened against them. So, some inclusion modalities need to find out by the educators based on the knowledge on the culture and oppressive cultural practices in different situations.

Social work educators need to work on the principle of anti-oppressive practice like social difference, linking personal and political context, exploration of power in personal \& structural levels. And also Reflexivity \& mutual involvement must be considered because it reflects on how values \& ethics, social difference and power affect the interactions between individuals (students) in a university setting or in a class room setting. These interactions are to be understood not only in psychological terms, but from sociological, historical, ethical, cultural and political terms as well. Only then success of anti-oppressive practice can be apprehended and assimilated in a class-room setting. Apart from these, social work educators need to address on the power and powerlessness because it is essential to understand how the differential access to power frame and construct relationships on any individual, group, community, organizational and societal level under the banner of anti-oppressive perspective.
A culturally relevant pedagogy can be developed which can benefit the educational system where social worker and educator can take efforts towards utilising anti-progressive perspectives for their practical challenges and inequality in day to day manner. Working on the capacities of the students and practitioners through home-school-college-university

partnership and building strength can help them to overcome structural inequalities and oppressive practices and social worker can do a lot in their practice setting eventually to provide justice through awareness and advocacy.

\section{References}

1. Abbate-Vaughn, J., Frechon, O and Wright, B.L. (2010). Accomplished Urban Teaching. Theory Into Practice. Vol. 49(3) ,pp. 185-192 , Taylor \& Francis, Ltd. Retrieved from https://www.jstor.org/stable/40890945 20-12-2019 08:00 UT.

2. Agrwal, D. and Gonsalves, C. (2005). Dalit and Law. Human Law Network, Delhi.

3. Basic Statistics of North Eastern Region. (2015). North East Council Secretariat. Retrieved from https://neccouncil.gov.in

4. Bipan Chandra. (1990). Freedom Struggle. Oxford University Press, New Delhi. Census. (2011). GOI.

5. Collins, Patricia Hill (2000). Black Feminist Thought: Knowledge, Empowerment and Consciousness. New York: Routledge.

6. Dalit Human Right Monitor. (2004). People's Watch. Tamil Nadu, Madurai.

7. Five Years Plans. (2012). Planning Commission. Government of India. Retrieved from https://www.planningcommission.gov.in.

8. Gallagher, K. (2016) . Can a Classroom Be a Family? Race, Space, and the Labour of Care in Urban Teaching. Canadian Journal of Education, Vol. 39(2), pp. 1-36 Canadian Society for the Study of Education Retrieved from

https://www.jstor.org/stable/10.2307/canajeducrevucan.39.2.02.

9. Hancock, A. M,. (2016). Intersectionality. An Intellectual History. USA : Oxford University Press.

10. Hooda, S. (2001). Contesting Reservations. Rawat Publications, Jaipur \& New Delhi. Jennings, I (1964) Law of the constitution, P.49 (3rd ed.).

11. Jennings, I. (1964). Law of the constitution, P.49 (3rd ed.). Lalwani, V. (2019). What next for transgender people, as India clears a bill that activists call "Murder of gender justice"?. Quartz India. 
12. Marc Gallanter. (1990). Law and Society in Modern India, Oxford University Press, New Delhi, P.185).

13.M.P. Jain. (1997). Indian Constitutional Law, Wadhwa and Company, Nagpur.

14. Mishra, N. (2001). Schedule Castes Education: Issues and Aspects. Kalpaz Publications, New Delhi.

15. Padmanabhan ,V. (2019) .Why the $10 \%$ quota may not make sense. Livemint

16. Sato, M. \&, Lensmire, T.J. (Jan. 2009). Poverty and Payne: Supporting Teachers to Work with Children of Poverty. The Phi Delta Kappan, Vol. 90(5), pp. 365-370. Retrieved from https://www.jstor.org/stable/20446115 20-12-2019 08:04 UTC

17. Seccombe, K. (2000). Families in poverty in the 1990s: Trends, causes, consequences, and lessons learned. Journal of Marriage and the Family, 62(4), 1094-1113.

18. Steinberg, S. (1998). The role of social science in the legitimization of racial hierarchy. Race and Society, vol-1 pp $5-14$.

19.The Indian Constitution. Retrieved from https://www.india.gov.in/sites/upload_files/npi/files/coi_part_f ull.pdf.

20. The World Bank. (2016). India's Poverty Profile. Retrieved from https://www.worldbank.org

21. Thorat, S. (2002), Oppression and Denial - Dalit Discrimination in the 1990s. Economic and Political Weekly, February.

22. Thorat, S. (2004). On Reservation Policy for Private Sector. Economic and Political Weekly, June.
23. Thorat, S. (2004). Remedies against economic discrimination: international experience of reservation policy in private sector. In Debroy, B. and Babu, S. (eds), The Dalit Question - Reforms and Social Justice, Globus, Delhi.

24. Thorat, S. (2005). Persistence of poverty: why do scheduled castes and scheduled tribes stay chronically poor? Chronic Poverty Research Centre, Working Paper, London.

25. Thorat, S., Negi, P. and Negi, A. ( 2005) (eds). Reservation and Private Sector - Quest Equal Opportunity and Growth. Rawat publication, New Delhi.

26. Tripathi, K. (2019). Upper caste quota: How to get certificate to avail $10 \%$ reservation. Financial Express.

27. UN General Assembly. (2015). Transforming our world: the 2030 Agenda for Sustainable Development.

28. Verinder Grover. (1998). Political Thinkers of India, Deep \& Deep Publications, New Delhi.

29. Vision NER. (2020). North East Council, India.

30. Weisskopf, T. (2004). Affirmative Action in the United States and India: A comparative perspective. Routledge, London.

31. V.N.Shukla. (1990). Constitutional law of India, Eastern Book Company Lucknow.

32. Zwart, de Frank. (2000). The Logic of Affirmative Action: Caste, Class and Quotas in India. Acta Sociologica. Vol 43 (3), PP 235-249

Citation: Dr. Sanjoy Roy, “Teaching Caste \& Reservation in Classroom Setting: Effort towards Anti-oppressive Social Work Practice”. American Research Journal of Humanities and Social Sciences, Vol 7, no. 1, 2021, pp. 1-8.

Copyright (C) 2021 Dr. Sanjoy Roy., This is an open access article distributed under the Creative Commons Attribution License, which permits unrestricted use, distribution, and reproduction in any medium, provided the original work is properly cited. 